\title{
Progesterone Receptor Expression and Score Differences in Determining Grade and Subtype of Meningioma
}

\author{
Jeni Poniman ${ }^{1}$ Muh Husni Cangara ${ }^{1}$ Cahyono Kaelan ${ }^{1} \quad$ Upik A. Miskad ${ }^{1}$ Gunawan Arsyadi \\ Mahmud Ghaznawe ${ }^{2}$ Dasril Daud ${ }^{3}$ Andi Ihwan ${ }^{4}$ Rohadi Muhammad Rosyidi ${ }^{5}$
}

${ }^{1}$ Department of Anatomical Pathology, Faculty of Medicine, Hasanuddin University, Makassar, Indonesia

2Faculty of Medicine, Muhammadiyah University, Makassar, Indonesia

${ }^{3}$ Department of Pediatrics, Faculty of Medicine, Hasanuddin University, Makassar, Indonesia

${ }^{4}$ Department of Neurosurgery, Faculty of Medicine, Hasanuddin

University Makassar, Indonesia

5 Department of Neurosurgery, Faculty of Medicine, Mataram University, West Nusa Tenggara Province General Hospital,

Mataram, Indonesia

J Neurosci Rural Pract 2020;11:552-557

\begin{abstract}
Address for correspondence Rohadi Muhammad Rosyidi, Department of Neurosurgery, Faculty of Medicine, Mataram University, West Nusa Tenggara Province General Hospital, Mataram 83127, Indonesia (e-mail: rha.ns2010@gmail.com).
\end{abstract}

\begin{abstract}
Keywords

- progesterone receptor

- meningioma

- WHO Grade

Background Meningioma is the most common brain tumor in which therapy and monitoring depend on the histopathological grade (World Health Organization [WHO] Grade). Progesterone receptor (PR) expression was reported positive in meningothelial cells and meningiomas with various degrees of positivity. We evaluated PR expression to determine its correlation with WHO Grade and each subtype of meningioma.

Materials and Methods This study used 70 samples of paraffin block that were diagnosed as meningioma and classified into WHO Grade I, II, and III. The paraffin blocks were sectioned in $5 \mu \mathrm{m}$ thickness and immunohistochemically stained with the anti-PR antibody.

Results PR expression was found positive in WHO Grade I and II groups, but negative in WHO Grade III group with the score of +2 found in clear cell and atypical subtype. These results were statistically significant with $p$-value $<0.05$.

Conclusion PR can be used as an additional marker to determine WHO Grade and subtype of meningioma.
\end{abstract}

\section{Introduction}

Meningioma is the most frequent brain tumor originating from meningothelial cells in the arachnoid layer with an incidence reported in the USA found in $36 \%$ in adults and $2.8 \%$ in children with a higher incidence in women. Meningioma is classified into grade I, II, and III based on World Health Organization (WHO) 2016 criteria. The incidence of each grade is $90 \%, 20$ to $25 \%$, and 1 to $6 \%$, respectively. ${ }^{1,2}$ Grade I meningioma generally could be treated with surgery followed by routine observations. However,Grade II meningioma needs a more complex approach such as subtotal resection, and radiotherapy must be done for the treatment of grade III meningioma. Besides therapy, monitoring after therapy also depends on the extent of tumor resection and grading. ${ }^{3,4}$ The WHO Grade is also the most useful predictor of recurrence, where Grade I, II, and III have recurrence 7 to $25 \%, 29$ to $52 \%$, and 50 to $94 \%$ in 20 years, respectively. ${ }^{2}$

It is important to determine the appropriate grade of meningioma based on WHO 2016 criteria to determine appropriate therapy and monitoring and to determine the patient's prognosis. However, there are some borderline cases that cannot meet the minimum criteria for a particular grade, so the additional marker is needed. 
Progesterone is an essential regulator of female reproductive function in the uterus, ovary, mammary gland, and brain, which also has an important role in nonreproductive tissues such as the cardiovascular system, bone, and central nervous system. ${ }^{5}$ Progesterone receptor (PR) expression is reported to be found positive in 50 to $80 \%$ meningioma $^{3}$ with various degrees of expression, generally inversely related to the grade of meningioma, Grade I has a positive expression, ${ }^{6-9}$ while Grade II and III have negative expressions or only show focal positive expressions. ${ }^{3}$ So, PR can be useful in borderline cases.,10

Based on the importance of clinical application and role in biological concepts, a study was conducted to evaluate PR expression in Meningioma WHO Grade I, II, and III.

\section{Materials and Methods}

This study was an analytic-observational study with a cross-sectional design, using paraffin blocks of central nervous system tumor that were diagnosed as meningioma in Anatomical Pathology Laboratories of DR. Wahidin Sudirohusodo Hospital, and Sentra Diagnostik Patologia, Makassar. Samples were grouped as Meningioma WHO Grade I, II, and III based on WHO 2016 grading system. This study was ethically approved by the Health Research Ethics Committee of Faculty of Medicine, Hasanuddin University. (457/H4.8.4.5.31/PP36-KOMETIK/2018).

\section{Immunohistochemical Staining for PR}

Paraffin blocks were sectioned in $5 \mu \mathrm{m}$ thickness by microtome and mounted on Poly-L-lysine object-glass. These tissue sections were deparaffinized with xylene and rehydrated with gradient alcohol. The endogenous peroxidase activity of tissue was blocked by $3 \%$ hydrogen peroxide for 10 minutes. The tissue sections were treated with retrieval antigen solution in the microwave for 20 minutes and protein block for 10 minutes, incubated with primary antibody anti-PR (DB-Biotech) for 30 to 60 minutes that was detected with secondary antibody for 10 minutes and conjugated with horseradish peroxidase for 15 minutes. The enzymes were labeled with 3,3'-diaminobenzidine for 10 minutes. The tissue sections were then counterstained with Mayer's hematoxylin, and covered with Entellan and deck glass.

\section{Immunohistochemical Staining Interpretation}

PR expression is an accumulation of PR protein at the nucleus that is stained brown as a positive expression by immunohistochemical staining. The expression was scored semiquantitively based on the staining intensity, a score of stained nuclei of the tumor cells. $(0=$ no staining, $1+=$ staining in $\leq 10 \%$ nuclei, $2+=$ staining in $11-50 \%$ nuclei, $3+=$ staining in $51-80 \%$ nuclei and, 4+ = staining in 81-100\% nuclei). PR expression was considered negative if scored as 0 and $1+(-$ Fig. 1$)$, and positive if scored as $2+, 3+$, and $4+\left(-\right.$ Fig. 2). ${ }^{11,12}$

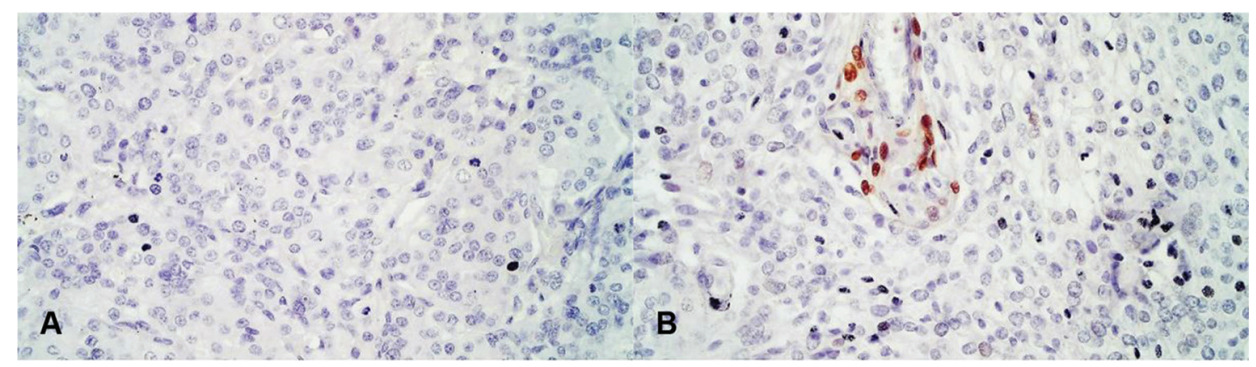

Fig. 1 Negative progesterone receptor (PR) expression. (A) PR score 0, (B) PR score 1+ (Anaplastic Meningioma, World Health Organization [WHO] Grade III). (400X)

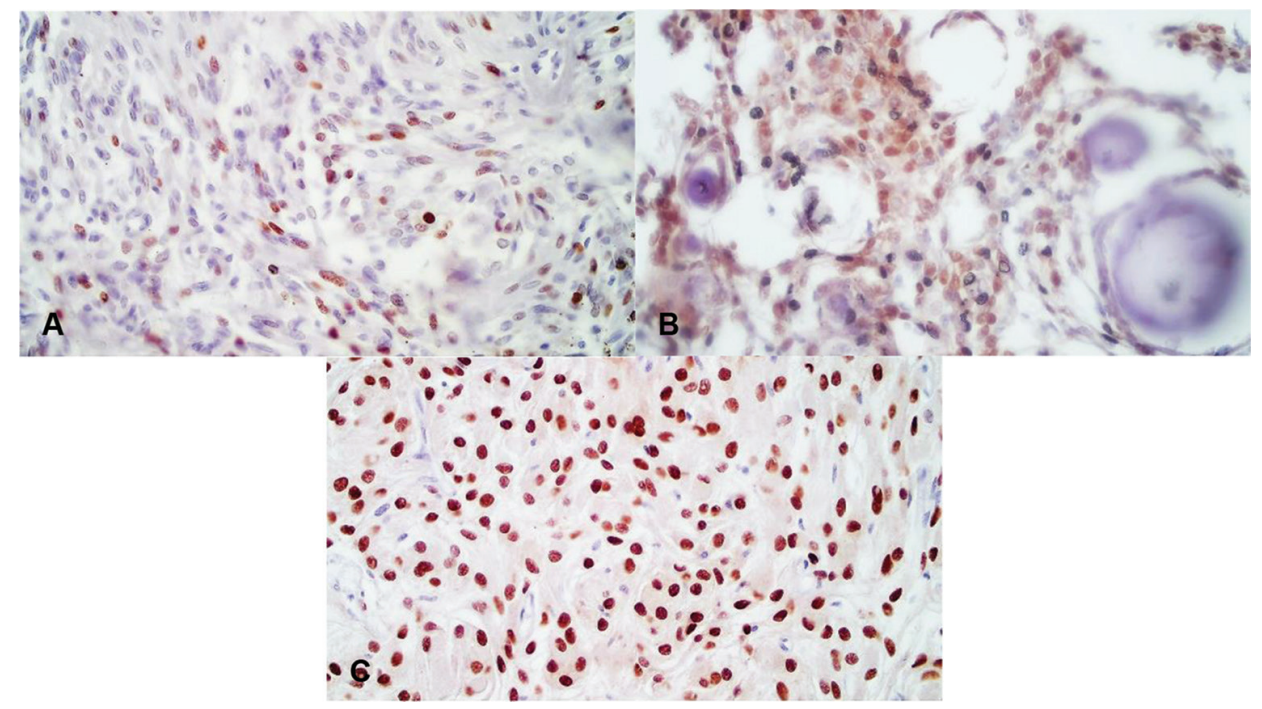

Fig. 2 Positive progesterone receptor (PR) expression. (A) PR score 2+ (Atypical Meningioma, World Health Organization [WHO] Grade II), (B) PR score 3+ (Psammomatous Meningioma, WHO Grade I), (C) PR score 4+ (Meningothelial Meningioma, WHO Grade I). (400X) 


\section{Statistical Analysis}

The results of this study were analyzed with SPSS (Statistical Package for Social Sciences) version 17 (IBM Company). The correlation of PR expression with Meningioma WHO Grade I, II, and III and its subtypes was analyzed with Mann-Whitney $\mathrm{U}$ and chi-squared tests.

\section{Results}

In this study, 70 samples were collected from the Anatomical Pathology Laboratories of DR. Wahidin Sudirohusodo Hospital and Sentra Diagnostik Patologia Makassar from January 2012 to June 2018 that were diagnosed as Meningioma WHO Grade I, II, and III as many as 27, 23, and 20 samples, respectively. The subtypes of each grade were Meningothelial, Fibrous, Transitional, Psammomatous and Microcystic; Chordoid, Clear Cell and Atypical; and Papillary and Anaplastic ( - Table 1).

The samples in this study consisted of 24 men and 45 women with a mean age of 49.26 (from the range of 17-98) years old ( - Table 1 ). The mean age of each Meningioma WHO Grade I, II, and III was 49.15, 47.3, and 51.65 years old, respectively, and the mean age with positive and negative PR expression was 48.3 and 51.65 years old, respectively. The distribution of sex and age is not significantly related to WHO Grade and PR expression (chi-squared test and one--way analysis of variance test; $p>0.05$ ). ( - Table 2 )

PR expression scores and PR expression in each Meningioma WHO Grade I, II, and III were 4+ and 3+ (positive $100 \%$ ), $4+$ and $2+$ (positive $100 \%$ ), and $1+$ and 0 (negative 100\%), respectively. These data indicates that there were differences in PR expression scores between Meningioma WHO Grade I and II, between WHO Grade I and III, and between WHO Grade II and III (Mann-Whitney U test; $p=0.000[p<0.01])$, and there were different PR expression in Meningioma WHO Grade I, II, and III (chi-squared test; $p=0.000[p<0.05]$ ). PR expression scores and PR expression based on subtypes of each Meningioma WHO Grade I, II, and III were Meningothelial, Fibrous, Transitional, and Microcystic
4+ (positive), and Psammomatous 4+ and 3+ (positive); Clear Cell and Atypical 2+ (positive), and Chordoid 4+ (positive); and Papillary 1+ and 0 (negative), and Anaplastic 1+ and 0 (negative). This data also showed that there were differences in PR expression scores and PR expression between each subtype of Meningioma WHO Grade I, II, and III (chi-squared test; $p=0.000[p<0.05])(-$ Table 3$)$.

Table 1 General characteristics

\begin{tabular}{|c|c|c|c|}
\hline \multicolumn{2}{|c|}{ Characteristics } & \multirow{2}{*}{$\begin{array}{l}n \\
25\end{array}$} & \multirow{2}{*}{$\begin{array}{l}\% \\
35.7\end{array}$} \\
\hline Gender & Male & & \\
\hline & Female & 45 & 64.3 \\
\hline \multirow[t]{3}{*}{ WHO Grade } & 1 & 27 & 38.6 \\
\hline & II & 23 & 32.9 \\
\hline & III & 20 & 28.6 \\
\hline \multirow[t]{10}{*}{ Subtypes } & Meningothelial & 6 & 8.6 \\
\hline & Fibrous & 6 & 8.6 \\
\hline & Mixed & 7 & 10 \\
\hline & Psammomatous & 5 & 7.1 \\
\hline & Microcystic & 3 & 4.3 \\
\hline & Chordoid & 7 & 10 \\
\hline & Clear cell & 2 & 2.9 \\
\hline & Atypical & 14 & 20 \\
\hline & Papillary & 2 & 2.9 \\
\hline & Anaplastic & 18 & 25.7 \\
\hline \multirow[t]{5}{*}{ PR Score } & 0 & 13 & 18.6 \\
\hline & $1+$ & 7 & 10.0 \\
\hline & $2+$ & 16 & 22.9 \\
\hline & $3+$ & 2 & 2.9 \\
\hline & $4+$ & 32 & 45.7 \\
\hline \multirow[t]{2}{*}{ PR Expression } & Positive & 50 & 71.4 \\
\hline & Negative & 20 & 28.6 \\
\hline
\end{tabular}

Abbreviations: PR, progesterone receptor; WHO, World Health Organization.

Table 2 Comparison between WHO Grade of Meningioma and PR expression to gender and age characteristics

\begin{tabular}{|c|c|c|c|c|c|c|c|}
\hline & \multicolumn{3}{|c|}{ WHO Grade } & \multirow[t]{2}{*}{$p$-Value } & \multicolumn{2}{|c|}{ PR Expression } & \multirow[t]{2}{*}{$p$-Value } \\
\hline & I (\%) & II (\%) & III (\%) & & $\begin{array}{l}\text { Positive } \\
\text { (\%) }\end{array}$ & $\begin{array}{l}\text { Negative } \\
\text { (\%) }\end{array}$ & \\
\hline Gender & & & & \multirow[t]{3}{*}{$0.174^{a}$} & & & \multirow[t]{3}{*}{$0.229^{a}$} \\
\hline Male & $6(22.22)$ & $10(43.48)$ & $9(45)$ & & $16(32)$ & $9(45)$ & \\
\hline Female & $21(77.78)$ & $13(56.52)$ & $11(55)$ & & $34(68)$ & $11(55)$ & \\
\hline \multicolumn{4}{|l|}{ Age } & \multirow[t]{5}{*}{$0.597^{b}$} & & & \multirow[t]{5}{*}{$0.365^{b}$} \\
\hline Mean & 49.15 & 47.30 & 51.65 & & 48.30 & 51.65 & \\
\hline Median & 49 & 48 & 51.50 & & 48.5 & 51.50 & \\
\hline Minimum & 26 & 26 & 17 & & 26 & 17 & \\
\hline Maximum & 89 & 68 & 98 & & 89 & 98 & \\
\hline
\end{tabular}

Abbreviations: PR, progesterone receptor; WHO, World Health Organization.

${ }^{a}$ Chi-squared test.

bone-way analysis of variance test. 
Table 3 Comparison between PR score and PR expression to WHO Grade of Meningioma and its subtypes characteristics

\begin{tabular}{|c|c|c|c|c|c|c|c|c|c|}
\hline & \multicolumn{5}{|c|}{ PR score } & \multirow[t]{2}{*}{$p$-Value } & \multicolumn{2}{|c|}{ PR expression } & \multirow[t]{2}{*}{$p$-Value } \\
\hline & $4+(\%)$ & $3+(\%)$ & $2+(\%)$ & $1+(\%)$ & $0(\%)$ & & $\begin{array}{l}\text { Positive } \\
\text { (\%) }\end{array}$ & $\begin{array}{l}\text { Negative } \\
\text { (\%) }\end{array}$ & \\
\hline WHO Grade & & & & & & \multirow{4}{*}{$0.000^{\mathrm{a}}$} & & & \multirow[t]{4}{*}{$0.000^{\mathrm{b}}$} \\
\hline 1 & 25 (92.59) & $2(7.41)$ & 0 & 0 & 0 & & $27(100)$ & 0 & \\
\hline II & $7(30.43)$ & 0 & $16(69.57)$ & 0 & 0 & & $23(100)$ & 0 & \\
\hline III & 0 & 0 & 0 & $6(30)$ & $14(70)$ & & 0 & $20(100)$ & \\
\hline \multicolumn{6}{|l|}{ Subtypes } & \multirow[t]{11}{*}{$0.000^{\mathrm{b}}$} & & & \multirow[t]{11}{*}{$0.000^{\mathrm{b}}$} \\
\hline Meningothelial & $6(100)$ & 0 & 0 & 0 & 0 & & $6(100)$ & 0 & \\
\hline Fibrous & $6(100)$ & 0 & 0 & 0 & 0 & & $6(100)$ & 0 & \\
\hline Mixed & $7(100)$ & 0 & 0 & 0 & 0 & & $7(100)$ & 0 & \\
\hline Psammomatous & $3(60)$ & $2(40)$ & 0 & 0 & 0 & & $5(100)$ & 0 & \\
\hline Microcystic & $3(100)$ & 0 & 0 & 0 & 0 & & $3(100)$ & 0 & \\
\hline Chordoid & $7(100)$ & 0 & 0 & 0 & 0 & & $7(100)$ & 0 & \\
\hline Clear Cell & 0 & 0 & $2(100)$ & 0 & 0 & & $2(100)$ & 0 & \\
\hline Atypical & 0 & 0 & $14(100)$ & 0 & 0 & & $14(100)$ & 0 & \\
\hline Papillary & 0 & 0 & 0 & $1(50)$ & $1(50)$ & & 0 & $2(100)$ & \\
\hline Anaplastic & 0 & 0 & 0 & $5(27.78)$ & $13(72.22)$ & & 0 & $18(100)$ & \\
\hline
\end{tabular}

Abbreviations: PR, progesterone receptor; WHO, World Health Organization.

aMann-Whitney U test.

${ }^{\mathrm{b}}$ Chi-square test.

\section{Discussion}

The risk of having meningioma increases with age. The tendency of women to have Grade I meningioma is higher than men, while for Grade II and III meningioma the tendency of men is higher than women. Because of the differences in gender, one of the other proposed etiology of meningioma is hormonal. ${ }^{2}$ But based on the data of age and gender in this study, there were no significant differences related to the distribution in WHO Grade I, II, and III meningioma and also no significant differences with PR expression. So that it supports the general etiologies of meningioma that are idiopathic and sporadic rather than the proposed one which is hormonal.,13 This is in line with the research conducted by Mukhopadhyay et al, which reported there was no relationship between age and WHO Grade ${ }^{9}$ and also another research conducted by Roser et al, which reported there was no relationship between sex and age with the PR expression. ${ }^{10}$

The data characteristics of this study based on WHO Grade I, II, and III were 27 (38.6\%), 23 (32.9\%), and 20 (28.6\%) samples, respectively, with each subtype consisting 6 Meningothelial (8.6\%), 6 Fibrous (8.6\%), 7 Transitional (10\%), 5 Psammomatous (7.1\%), and 3 Microcystic (4.3\%) samples (Grade I); 7 Chordoid (10\%), 2 Clear Cell (2.9\%), and 14 Atypical (20\%) samples (Grade II); and 2 Papillary (2.9\%) and 18 Anaplastic (25.7\%) samples (Grade III). This is in accordance with the nature of meningioma that is a slow-growing neoplasm and generally benign so that the incidence of Meningioma WHO Grade I is more common than WHO Grade II and III, with the subtypes commonly are Meningothelial and Transitional., 2,14
Progesterone is an essential regulator of reproductive function and also plays an important role in nonreproductive tissues such as the cardiovascular system, bone, and central nervous system. ${ }^{5}$ In the central nervous system, progesterone is a neurosteroid and has a variety of important roles. Besides that, progesterone is also an indirect precursor of cortisol. Cortisol itself has a role in the response to stress and has an anti-inflammatory effect. ${ }^{15}$ Progesterone is normally expressed in non-neoplastic meningothelial cells in small amounts, which then increases when there is cell proliferation, such as in meningioma, and decreases when there are changes in cell differentiation. ${ }^{16}$ However, this progesterone expression is not under the influence of the estrogen as in reproductive organs. ${ }^{9,12,17}$ Meningothelial cells primarily line the edges of arachnoid granulation so-called arachnoid cap cells, ${ }^{18}$ and this arachnoid granulation plays a role in the absorption of cerebrospinal fluid into dural sinuses. ${ }^{17,19}$ The role of PR in the regulation of the fluid transportation is not yet clear, but there are some indications that steroid hormones can play a role in which glucocorticoid dexamethasone is reported to increase the absorption of cerebrospinal fluid into the sagittal sinus. In addition, metabolites from progesterone and mineralocorticoid deoxycorticosterone have been reported to modulate the function of the receptor-operated chloride channel in the nervous system, which is associated in fluid and ion transportation. ${ }^{17}$

$\mathrm{PR}$ expression in meningioma is inversely related to WHO Grade, which in WHO Grade I there is an increase of 50 to 90\% PR expression; so it shows positive PR expression while in WHO Grade II and III there is a loss of 60 to $80 \%$ and 80 to 90\% PR expression, respectively; so it shows focal or negative 
PR expression. ${ }^{13}$ Almost all WHO Grade III shows negative expression. ${ }^{2}$ In this study, obtained PR expression scores 4+ and 3+ were found in WHO Grade I, 4+ and 2+ were found in WHO Grade II, and 1+ and 0 were found in WHO Grade III, with $100 \%$ positive PR expression in WHO Grade I and II, and $100 \%$ negative in WHO Grade III. These data showed significant differences in PR expression scores and PR expression in Meningioma WHO Grade I, II, and III. Based on each subtype, a score of 4+ was obtained 100\% in Meningothelial, Fibrous, Transitional, and Microcystic (WHO Grade I), 60\% in Psammomatous (WHO Grade I) and 100\% in Chordoid (WHO Grade II); 3+ was obtained 40\% in Psammomatous; 2+ was obtained 100\% in Clear Cell and Atypical (WHO Grade II); 1+ was obtained 50\% in Papillary and 27.78\% in Anaplastic (WHO Grade III); and 0 was obtained 50\% in Papillary and $72.22 \%$ in Anaplastic (WHO Grade III). This result is in line with the other studies, which reported that positive PR expression was found more in WHO Grade I than II and negative PR expression was found in WHO Grade III. ${ }^{6-8,10,16}$ In one study, Ikeri et al reported that PR expression scores decrease along with the increasing of grade in which PR expression scores of WHO Grade I were higher than II and III, and WHO Grade II was higher than III. ${ }^{16}$

Based on these data from this study, PR expression scores and PR expression can be used to help diagnose Meningioma WHO Grade I, II, and III, especially for Atypical and Anaplastic subtypes that are sometimes difficult to diagnose using 2016 WHO criteria, because there are some cases that cannot meet the minimum diagnostic criteria (borderline cases), while the other subtypes were diagnosed based on each its histopathological characteristics.

Other studies also recommended PR expression to be used as a routine marker to help assess the nature of meningioma, which can distinguish the degrees of differentiation with the value inversely related to WHO Grade, although there was the same value between WHO Grade I and II, both had a positive expression. ${ }^{7,8,10,16}$ Roser et al added that PR expression should be combined with other markers to help assess the nature of meningioma, and also to predict recurrence and to determine more effective follow-up strategies. ${ }^{10}$

\section{Conclusion}

We can conclude that if the PR expression is negative, then it is grouped into WHO Grade III, and if the PR expression is positive, then it is grouped into WHO Grade I and II. If the PR expression score is +2 , then it is grouped in WHO grade II with Clear Cell or Atypical subtypes. Based on this, PR expression can be used as an additional marker to help determine WHO grade and several subtypes especially in borderline cases.

\section{Highlights}

- Meningioma is the most common brain tumor which therapy and monitoring depend on the histopathological grade (WHO Grade).

- Progesterone is not only an essential regulator of reproduction but also has an important role in the nonreproductive organ as in the central nervous system.
- PR expression was reported positive in meningothelial cells and meningiomas with various degree of positivity.

- There was a significant correlation between PR expression to WHO Grade of meningioma and its subtypes.

\section{Conflict of Interest}

None declared.

\section{References}

1 Kleinschmidt-DeMasters B, Rodríguez FJ, Tihan T, Neoplastic: meninges. In: Kleinschmidt-DeMasters B, Rodríguez FJ, Tihan T, eds. Diagnostic Pathology: Neuropathology. 2nd edition. Philadelphia: Elsevier; 2016:450-467

2 Perry A, Louis DN, Budka H, et al. Meningioma. In: Louis DN, Ohgaki H, Wiestler OD, Cavenee WK, eds. WHO Classification of Tumours of the Central Nervous System. Revised 4th edition. Lyon: International Agency for Research on Cancer (IARC); 2016:232-237

3 Perry A, Meningiomas. In: Perry A, Brat DJ, eds. Practical Surgical Neuropathology: A Diagnostic Approach. 1st edition. Philadelphia: Churchill Livingstone an affiliate of Elsevier Inc; 2010:185-217

4 Goldbrunner R, Minniti G, Preusser M, et al. EANO guidelines for the diagnosis and treatment of meningiomas. Lancet Oncol 2016;17(9):e383-389

5 Scarpin KM, Graham JD, Mote PA, Clarke CL. Progesterone action in human tissues: regulation by progesterone receptor (PR) isoform expression, nuclear positioning and coregulator expression. Nucl Recept Signal 2009; 7:e009

6 Wolfsberger S, Doostkam S, Boecher-Schwarz HG, et al. Progesterone-receptor index in meningiomas: correlation with clinico-pathological parameters and review of the literature. Neurosurg Rev 2004;27(4):238-245

7 Shayanfar N, Mashayekh M, Mohammadpour M. Expression of progesterone receptor and proliferative marker Ki 67 in various grades of meningioma. Acta Med Iran 2010;48(3):142-147

8 Mukherjee S, Ghosh SN, Chatterjee U, Chatterjee S. Detection of progesterone receptor and the correlation with Ki-67 labeling index in meningiomas. Neurol India 2011;59(6):817-822

9 Mukhopadhyay M, Das C, Kumari M, Sen A, Mukhopadhyay B, Mukhopadhyay B. Spectrum of meningioma with special reference to prognostic utility of ER, PR and Ki67 expression. J Lab Physicians 2017;9(4):308-313

10 Roser F, Nakamura M, Bellinzona M, Rosahl SK, Ostertag H, Samii M. The prognostic value of progesterone receptor status in meningiomas. J Clin Pathol 2004;57(10):1033-1037

11 El-Badawy NM, Farid RM, Nagib LN, Ibrahim RA. Role of progesterone receptor expression and proliferative activity in predicting the recurrence of meningioma. Egypt J Pathol 2013:76-81

12 Shanthi V, Grandhi B, Mohan Rao N, Sundar Rao BS, Muram Reddy VL. Assessing the prognostic importance of ER, PR expression in meningiomas by comparing with proliferative rate using Ki67. Indian J Pathol Res Pract. 2017;6(2):431-434

13 Perry A, Meningioma. In: Perry A, Brat DJ, eds. Practical Surgical Neuropathology: A Diagnostic Approach. 2nd edition. Philadelphia: Elsevier; 2018:259-298

14 Perry A, Louis DN, Budka H, et al. Meningioma variants. In: Louis DN, Ohgaki H, Wiestler OD, Cavenee WK, eds. WHO Classification of Tumours of the Central Nervous System. Revised 4th edition. Lyon: International Agency for Research on Cancer (IARC); 2016: 237-245

15 Santarsieri M, Niyonkuru C, McCullough EH, et al. Cerebrospinal fluid cortisol and progesterone profiles and 
outcomes prognostication after severe traumatic brain injury. J Neurotrauma 2014;31(8):699-712

16 Ikeri NZ, Anunobi CC, Bankole OB. Progesterone receptor expression and Ki-67 labelling index of meningiomas in the Lagos university teaching hospital. Niger Postgrad Med J 2018;25(1):17-20 www.npmj.org [Internet]

17 Verhagen A, Go KG, Visser GM, Blankenstein MA, Vaalburg W. The presence of progesterone receptors in arachnoid granulations and in the lining of arachnoid cysts: its relevance to expression of progesterone receptors in meningiomas. $\mathrm{Br} \mathrm{J}$ Neurosurg 1995;9(1):47-50

18 Brat DJ, Normal brain histopathology. In: Perry A, Brat DJ, eds. Practical Surgical Neuropathology: A Diagnostic Approach. Philadelphia: Churchill Livingstone an affiliate of Elsevier Inc; 2010 15-33

19 Lopes MBS, Meninges: embryology. In: Lee JH, ed. Meningioma. London: Springer; 2009:25-29 